\title{
Persistent vegetative state and withdrawal of nutrition and hydration
}

\author{
Raanan Gillon Imperial College Health Service and St Mary's Hospital Medical School, London University
}

In a helpful paper in this issue of the journal Dr Mitchell and colleagues discuss the moral issues associated with the management of persistent vegetative state (PVS). They argue for the moral legitimacy of withdrawing all medical treatment, including artificial nutrition and hydration (ANH), from PVS patients in whom the diagnosis of an irreversibly unconscious state has been established as 'highly probable' (1). While ever since the famous case of Karen Quinlan these issues have been discussed in many American legal cases and papers in the bioethics literature (2), the issue became highly topical in England earlier this year when the House of Lords considered its first PVS case and ruled that doctors could lawfully withdraw life-supporting medical treatment, including nutrition and hydration, from a PVS patient, Anthony Bland (3).

In their analysis Mitchell et al focus on what since Hippocratic times has been the moral core of health care, indeed its moral sine qua non, namely the obligation to provide medical benefit for the patient. In reliably diagnosed PVS it is, they argue, impossible to provide any such benefits and thus any treatment is futile - a term also used recurrently by Lord Goff in his judgement on the Bland case (3). The term 'futile' is acquiring a substantial medical literature but it is very simply defined in the Oxford English Dictionary as 'useless, ineffectual, vain, . . lacking in purpose', and those ideas are at the heart of the various medical uses of the term. In addition to the references provided by Mitchell et al a useful synopsis of the various medical applications of the term is provided by Brody in a footnote to the Appleton International Conference Guidelines on foregoing life-prolonging medical treatment (4). The most narrowly defined sense of medical futility is a treatment that cannot produce the intended physiological changes - for example cardiac compression, or mechanical ventilation of a dead body with a dead heart is futile in this sense - as, at the other end of the spectrum, is giving antibiotics for a viral infection. Ventilation of a brain-dead body with a functioning heart may not be futile in a physiological sense, in that it may achieve the physiological objective of oxygenation of the body's organs and thus keep them in good condition for subsequent transplantation. Such an outcome would be compatible with Brody's second sense of medical futility: where the physiological objective is achieved (oxygenation of organs) but where there is no benefit to the patient (for example because the patient remains dead; or, as in permanent coma or as in PVS, permanently unconscious). A third sense of medical futility is where the patient achieves some benefit, but of such a minimal degree that the doctor thinks the treatment is futile; this category should probably be split into two subcategories - minimal benefit without corresponding harm for the patient (for example, resuscitation to a state of severe brain impairment involving consciousness but no suffering); and resuscitation involving minimal or more benefit but with major harm outweighing that benefit - for example if the patient is resuscitated to a self-aware life of major and irremediable suffering.

Brody points out, like Dr Mitchell and colleagues, that in addition to such qualitative considerations underpinning the ascription of futility there are also quantitative considerations - at some degree of improbability of success a proposed or actual treatment can be deemed futile in each of these types of case.

Major problems arise, Brody goes on, when a further medical use of the term is employed; notably for treatments which the doctors (or even 'the vast majority of people') consider more harmful than beneficial but which in the patient's view does or would produce net benefit. Here there would seem to be little doubt that there is simply a clash of opinion about what constitutes net benefit for the patient; essentially the issue is not so much about the meaning of futility, but whose assessment in a particular case or type of case should count.

It would be a deceitful use of words to trade on these ambiguities in the use of the term 'futile' to try and disguise any such disagreement by using the term as though it was merely making a technical medical judgement, based on medical expert assessment, as in the case of the first use. Indeed the ambiguity in the medical use of the term 'futile' suggests that either it should be avoided altogether in the highly emotive arena of PVS or that those who use it always specify which of the various uses they intend. In particular, when there is disagreement between patients' surrogates and doctors or other health-care workers - 
or indeed between health-care workers themselves on the question of futility - it is probably wiser to shift to the underlying theme of benefit: how much benefit for the patient does the proposed management offer? For unresolved disputes a judicial forum or alternatively perhaps an intermediate multidisciplinary ethics committee seem to be necessary (5).

In coming to such decisions there is unfortunately a deep chasm between the large majority of people who believe that a life of permanent unconsciousness is not a benefit and a small minority who believe either that any type of life is a benefit, or alternatively that whether it is a benefit or not it must be maintained - one version of the so-called sanctity of life doctrine. In the context of medicine the chasm lies between the majority of doctors for whom the purpose of preserving their patients' lives is instrumental, as a means of helping their patients regain or maintain a life that they, the patients, consider worth living; and those doctors for whom the preserving of life is an end in itself, regardless of the quality or nature of that life, regardless of the patients' views about whether or not the life is worth living; and, it almost goes without saying for such vitalists (for that is the proper term for such a stance), regardless of the cost to others of preserving those lives. For such people - thankfully only a small minority, but often a loudly vocal minority - this vitalist version of the sanctity of life doctrine takes moral precedence over respect for the autonomy of the patient, over considerations of harm and benefit, and over considerations of justice whether in the context of distribution of scarce resources, respect for people's rights or respect for morally acceptable laws (though they may simply assert that laws that oppose this vitalist stance are ipso facto morally unacceptable).

It is important to realise that the divide between vitalists and those who believe that life is only valuable if it is a means to the Good Life - a life that the person concerned finds (or will find) a life worth living - is not a religious divide. Rather it is a divide that separates a certain sort of moral fundamentalist from the rest of us, of whatever religion or none, for neither in the major religions nor outside them is there to be found a predominance of vitalism, of the creed that a life of permanent unconsciousness is a life worth living.

But what of those who do hold these beliefs? We must assume that should they become permanently vegetative their wish would be to be maintained alive but unconscious indefinitely - perhaps for more than thirty years. English law now states that people who have clearly specified that they do not wish to be maintained in PVS should have their wishes respected. In the absence of any such clear directions a court may permit withdrawal of ANH if the PVS patient's surrogates and doctors agree that it is not in his or her interests to continue with them (3). But the law remains silent on the question of what should be done if a PVS patient's surrogates disagree with doctors who advise withdrawal of $\mathrm{ANH}$, either because maximal prolongation of life was the patient's prior expressed wish (perhaps in an advance directive) or because they believe it to be in the patient's interests to maintain $\mathrm{ANH}$ - and perhaps other life-prolonging treatments - indefinitely, until the patient dies despite such interventions. In such cases moral arguments based on respect for the patient's autonomy (or by proxy as expressed by his proper surrogate) indicate that treatment should be maintained. Harm/benefit analyses so far as the patient is concerned, given that these should prima facie be heavily influenced by the patient or his proper surrogates, also indicate that such treatment should be maintained.

Nonetheless there remains the moral requirement of justice; and in the context of scarce and relatively fixed health-care resources, such as those of national health-care systems and of some sorts of insurancebased health-care systems, justice requires consideration of the opportunity costs both to other potential recipients of those scarce resources, and to those who provide the funding for those resources, either through their taxes or through their insurance premiums. Many such people will consider that expenditure of significant resources on prolonging permanently unconscious lives is a waste of those resources.

It is a debate that the public and their representatives will be faced with increasingly as ever more and clearly beneficial treatments are developed, at everincreasing cost. Increasingly, it may be predicted, they will decide that some sorts of treatment, while they can be provided privately for those who find them beneficial, either paid for by their recipients or by charitable well-wishers, should not be funded by the state at the expense of obviously more beneficial treatments. It is probably also safe to predict that treatment to prolong the lives of patients reliably diagnosed to be in PVS will for many constitute a paradigm for such treatments that, in the context of scarce resources, should not be funded by the state.

\section{References}

(1) Mitchell K R, Kerridge I H, Lovat T J. Medical futility, treatment withdrawal and the persistent vegetative state. Fournal of medical ethics 1993; 19: 71-76.

(2) McCarrick P M. Withholding or withdrawing nutrition or hydration: scope note 7 . Washington DC: National Reference Center for Bioethics Literature, Kennedy Institute of Ethics, 1992.

(3) Withdrawal of medical treatment from hopeless case not unlawful. (Law report). The Times 1993 Feb 5: 8.

(4) The Appleton international conference: developing guidelines for decisions to forgo life-prolonging medical treatment. Fournal of medical ethics (supplement), 1992; 18: 8 (footnote 9).

(5) Jennett B. Letting vegetative patients die - ethical and lawful and brings Britain into line. British medical journal 1992; 305: 1305-1306. 